\title{
Immunological and epidemiological factors affecting candidiasis in HIV patients beginning antiretroviral therapy in an Asian clinic
}

\author{
Endah A.T Wulandari ${ }^{1,2}$, Henny Saraswati ${ }^{1}$, Robiatul Adawiyah ${ }^{1}$, Samsuridjal Djauzi $^{1,2}$, Retno \\ Wahyuningsih ${ }^{1,3}$, Patricia Price ${ }^{1,4}$ \\ ${ }^{1}$ Faculty of Medicine, Universitas Indonesia, Jakarta, Indonesia \\ ${ }^{2}$ Cipto Mangunkusumo Hospital, Jakarta, Indonesia \\ ${ }^{3}$ Faculty of Medicine, Universitas Kristen Indonesia, Jakarta, Indonesia \\ ${ }^{4}$ School of Biomedical Science, Curtin University, Bentley, Australia
}

\section{Corresponding author:}

A/Professor Patricia Price

School of Biomedical Science

Curtin University

Bentley WA

Australia

Tel: +61 892669716

Email: patricia.price@curtin.edu.au

Key words: HIV, oropharyngeal candidiasis, $\beta$-defensin, total fungal burden, Candida albicans

Running Heading: Oropharyngeal candidiasis in HIV patients 


\begin{abstract}
Objectives: Oropharyngeal candidiasis (OPC) is common in HIV patients beginning antiretroviral therapy (ART). Here we address the response to ART, and the roles of poor oral hygiene and defects in local innate immunity with a focus on salivary $\beta$-defensins, as they are implicated in control of candidiasis but have not been investigated in this context.
\end{abstract}

Design: ART naïve HIV-infected adults $(\mathrm{n}=82)$ with $<200 \mathrm{CD} 4^{+} \mathrm{T}$-cells $/ \mathrm{mm}^{3}$ attending clinics at at Cipto Mangunkusumo Hospital, Jakarta, were examined at the commencement of ART, and 73 were re-examined after 3 months. OPC was detected by clinical examination, and candida and fungal burdens were determined following culture on CHROMagar and saboroud-dextrose agar (resp). Salivary $\beta$-defensins (-2 and -3 ) were quantified by ELISA. Healthy control subjects $(\mathrm{n}=40)$ matched the patients by age and gender.

Results: OPC was evident in 47 patients before ART, and associated with greater fingal burdens. No OPC was detected in healthy controls and culture positivity was rare. ART decreased the prevalence of OPC to 8/73 HIV patients re-examined after 3 months, with reduced total fungal and C. albicans burdens. The incidence of OPC was independent of oral hygiene. Hyposalivation was more common in untreated HIV patients (16\%) than after 3 months on ART and was rare in healthy controls. HIV patients were also more likely to have acidic saliva. Salivary $\beta$-defensin- 2 was elevated in the presence of $C$. albicans pseudohyphae and OPC after 3 months on ART, but $\beta$-defensin-3 was not affected by OPC or ART.

Conclusions: ART reduces the prevalence of OPC, and the total fungal and C. albicans burden. Levels of salivary $\beta$-defensin- 2 may associate with OPC in HIV patients responding to ART. 


\section{Introduction}

Oropharyngeal candidiasis (OPC) accounts for about $50 \%$ of opportunistic infections among HIV patients, with higher rates in developing countries (Leao, Ribeiro, Carvalho, Frezzini, \& Porter, 2009). However few studies have addressed this important condition in patients beginning ART administered under current WHO guidelines or evaluated factors affecting risk. Low $\mathrm{CD}^{+}$T-cell counts and high plasma HIV RNA levels have been associated with oral disease in HIV patients. The low $\mathrm{pH}$ of saliva, reduced salivary flow rate and poor oral hygiene are risk factors for fungal infection in people without HIV (Muzurovic, Babajic, Masic, Smajic, \& Selmanagic, 2012) and may be important in HIV patients. ART reduces mortality and morbidity, including the oral manifestations of HIV/AIDS (Gonc et al., 2013; Taiwo \& Hassan, 2010). However pseudomembranous oral candidiasis can develop on ART (Espinosa, Ormsby, \& Gonza, 2009).

Saliva contains antimicrobial proteins which inhibit microbial colonization (Alves et al., 2014; (Nittayananta, Kemapunmanus, Amornthatree, Talungchit, \& Sriplung, 2014); Khan et al., 2013). Human $\beta$-defensins (hBD) are produced by epithelial cells in the buccal mucosa, gingiva, tongue, salivary glands and other parts of the mouth (Diamond \& Ryan, 2012; Chung, Dommisch, Yin, \& Dale, 2007; Abiko, Nishimura, \& Kaku, 2003). hBD-2 and hBD-3 are known

as inducible $\beta$ defensins, which are found at low level under normal conditions and induced by microbial colonization and inflammation, for example in Candida infection (Diamond \& Ryan, 2012; Hans \& Hans, 2014). Production of hBD-2 increases in the presence of Candidiasis, oral lichen planus and leukoplakia in patients without HIV (Abiko et al., 2002). hBD-2 and hBD-3 are induced by TNF- $\alpha$ and interferon- $\gamma$ with inhibition by IL-4 and IL-13 (Albanesi et al., 2007).

This study investigates factors which may play role in the occurrence of OPC and/or may influence the total fungal burden in HIV-infected patients commencing ART. These include Tcell recovery, oral hygiene, unstimulated salivary flow rate, salivary $\mathrm{pH}$, smoking, alcohol consumption and salivary $\beta$-defensins. Smoking can promote many oral pathologies, including candidiasis (Soysa \& Ellepola, 2005). Specifically smoking has been associated with the occurrence of pseudomembraneous oral candidiasis, while alcohol consumption was associated 
with erythematous type of oral candidiasis (Gonc et al., 2013). Smoking and alcohol may affect saliva. Alcohol consumption can cause sialosis (infiltration of adipose into the salivary gland) and thus alter the salivary flow rate and its components (Carda et al., 2004). Smoking can reduce salivary flow rate and salivary $\mathrm{pH}$. These changes may be accompanied by reduced salivary antimicrobial components (Soysa \& Ellepola, 2005).

\section{Materials and Methods}

\section{Subjects and oral health examinations}

ART-naïve HIV-infected adult patients ( $\mathrm{n}=82$ ) with $<200 \mathrm{CD} 4^{+} \mathrm{T}$ cells $/ \mathrm{ml}$ were examined at the HIV clinic of an inner city tertiary hospital (Cipto Mangunkusumo Hospital, Jakarta) and 73 were re-examined 3 months after commencing triple therapy including lamivudine, zidovudine, nevirapine, stavudine, efavirens or tenofovir. Nine patients couldn't be re-examined at three months as they had died from conditions related to AIDS (5 patients), refused to continue ( 2 patients), experienced a severe drug-induced allergy requiring discontinuation of ART (1 patient) or were lost to follow up (1 patient). Hepatitis B and $\mathrm{C}$ were diagnosed serologically and pulmonary tuberculosis by chest $\mathrm{x}$-ray and sputum microscopy. $\mathrm{CD} 4^{+} \mathrm{T}$ cells and plasma HIV RNA, oral total fungal burden and oral health were assessed. Forty healthy controls were included, matched to the patients by age and gender. Ethical approval for this study was obtained from Health Research Ethic Committee Faculty of Medicine Universitas Indonesia \& Cipto Mangunkusumo Hospital (no: 26/H2.F1/ETIK/2013).

All oral examinations were performed by one oral medicine specialist (EW), so no interexaminer calibration was needed. Oral hygiene was assessed using Oral Hygiene IndexSimplified [OHI-S; (Greene \& Vermillion, 1964)], based on the presence of debris and calculus. Gingival health was assessed using the Gingival Index (Benamghar, Penaud, Kaminsky, \& Abt, 1982). Unstimulated salivary flow rate was determined from the volume of saliva collected over 5 minutes of spitting into a plastic tube. Hyposalivation was defined as a flow rate of $<0.1$

$\mathrm{ml} /$ minute (Humphrey \& Williamson, 2001). Salivary $\mathrm{pH}$ was assessed immediately using $\mathrm{pH}$ indicator strips (range $0-14$ ). At least $1 \mathrm{ml}$ whole saliva was then collected by spitting into a 
plastic tube, centrifuged (5 mins, $3500 \mathrm{rpm}$ ), supplemented with $0.5 \mathrm{M}$ Phenylmethylsulfonyl Fluoride [PMSF] $(1: 10)$ and stored at $-80^{\circ} \mathrm{C}$ for salivary protein analyses.

\section{Diagnosis of oropharyngeal candidiasis and detection of fungal colonization.}

Diagnoses of pseudomembranous or erythematous OPC were based on a clinical appearance of removable white plaques or atrophic erythematous areas of the oral mucosa (Muzurovic et al., 2012). Clinical diagnostic of OPC was supported by the presence of pseudohyphae as the pathogenic form of Candida). After the examination and sampling described above, an oral rinse was performed using $10 \mathrm{ml}$ saline and patients were asked to spit into a sterile container for mycology screening. These samples were streaked onto glass slides to visualise Candida yeast and pseudohyphae and onto Sabouraud Dextrose Agar (Oxoid; Basingstoke, UK; incubated at $34^{\circ} \mathrm{C}$ ) to assess total fungal burden and CHROMagar ${ }^{\mathrm{TM}}$ (Paris, France; incubated at $37^{\circ} \mathrm{C}$ ) to assess Candida albicans. Colony-forming units (CFU) were counted manually after 48 hours. Total fungal and Candida albicans burden was classified as mild-to-moderate $(<50 \mathrm{CFU} / \mathrm{ml})$ or strong ( $\geq 50 \mathrm{CFU} / \mathrm{ml}$ ) (Torres, Peixoto \& Caldas, 2002).

\section{Salivary $\beta$ defensins}

96-well plates were coated with $0.83 \mu \mathrm{g} / \mathrm{ml} \beta$-defensin coating antibody (Abcam; Cambridge, MA, USA) overnight in $4^{\circ} \mathrm{C}$, washed using PBS $0.05 \%$ Tween 20, and blocked using 5\% bovine serum albumin (BSA) in PBS at room temperature (1 hour). Samples were diluted in PBS with $2 \%$ BSA and added to the plates ( 2 hours), followed by $0.83 \mu \mathrm{g} / \mathrm{ml} \beta$-defensin biotinylated antibody (1 hour) and streptavidin-horse radish peroxidise (1 hour). TMB substrate was applied for 20 minutes, reactions were stopped with $\mathrm{H}_{2} \mathrm{SO}_{4}$ and plates were read at $450 \mathrm{~nm}$. Data were read from standard curves prepared using aliquots of a pooled sample assigned a value of 1000 arbitrary units $(\mathrm{AU}) / \mathrm{ml}$.

\section{Statistics}

Controls and $\mathrm{HIV}^{+}$groups were compared using non-parametric Mann-Whitney tests, while longitudinal data were assessed using Wilcoxon matched pair tests. Categorical data were assessed by $\mathrm{Chi}^{2}$ tests. P-values $<0.05$ were accepted as indicating a significant difference and $\mathrm{p}<0.10$ is noted as suggesting a trend. 


\section{Results}

\section{Patient demographics}

HIV patients and control groups had more male subjects $(67.5 \%$ for healthy controls, $68.3 \%$ for HIV patients, $\mathrm{p}=1.00)$. Median (range) ages were 30 (18-46) years for healthy controls and 31(19-49) years for HIV patients $(\mathrm{p}=0.40) . \mathrm{CD}^{+} \mathrm{T}$ cell counts rose on ART and plasma HIV RNA levels decreased so that only $8.2 \%$ of patients had $>10,000$ copies HIV-1 RNA/ml after 3 months. 29\% of patients had hepatitis (B and/or C), and 52\% were infected with Mycobacterium tuberculosis. 57\% of HIV patients were current or past smokers, compared with $50 \%$ of healthy controls. $27 \%$ reported moderate alcohol consumption, most declaring that they had ceased in the last 12 months. This is not significantly greater than controls (12.5\%, data not shown). Oral hygiene was similar in the patients and healthy controls [see Table 1]. Unstimulated salivary flow rates similar in controls and untreated patients, but increased on ART ( $\mathrm{p}=0.001)$. Compared to healthy controls, more HIV patients had saliva $\mathrm{pH}$ below 7 at baseline and after 3 months on $\operatorname{ART}(\mathrm{p}=0.002)$.

Clinically apparent OPC often resolves on ART, but the total fungal and Candida albicans burdens remain high

OPC was diagnosed in 57\% of ART-naive HIV patients. The prevalence decreased by 3 months on ART but OPC remained in $11 \%$ of subjects [Table 1]. No healthy control subjects had OPC. Compared to healthy controls, a high total fungal burden was more common in HIV patients before and on ART. Strong total fungal burdens were less common after 3 months on ART (p=0.04). Apart from Candida albicans, we identified C. krusei, C. tropikalis, C. glabrata, C. parapsilosis and C. dubliniensis - mostly in patients with a low fungal burden. C. albicans remained more common in patients than controls, but the incidence decreased on ART.

OPC is seen in patients with a high fungal burden and unrelated co-infections

A diagnosis of OPC was clearly associated with the total fungal burden assessed at baseline. Among patients with OPC, $100 \%$ had a total fungal burden $\geq 50 \mathrm{CFU} / \mathrm{ml}$ and $98 \%$ had a Candida albicans burden $\geq 50 \mathrm{CFU} / \mathrm{ml}$. We observed a a weak association between OPC and high HIV RNA [Table 2], but this did not achieve statistical significance. Tuberculosis co-infection among 
ART-naïve HIV patients associated significantly with the presence of OPC $(\mathrm{p}=0.05)$, and more subjects with hepatitis B or C co-infection had OPC $(\mathrm{p}=0.02)$ [Table 3].

The presence of OPC was not associated with salivary flow rate or salivary $\mathrm{pH}$ [Table 2] or with the daily frequency of tooth brushing, antiseptic mouthwash gargling, smoking or alcohol consumption ( $p>0.05)$. Smoking and alcohol consumption were not associated with OPC $(\mathrm{p}=0.53, \mathrm{p}=0.8$, resp. $)[$ Table 3$]$.

Salivary $\beta$ defensin-2 may be affected by HIV or OPC

Salivary hBD-2 levels were similar in healthy controls and treated patients, and marginally higher $(\mathrm{p}=0.09)$ in untreated patients [Table 1]. Further analyses showed a small decline in salivary hBD-2 levels on ART in patients without OPC $(\mathrm{p}=0.08)$ or with a low burden of Candida $(\mathrm{p}=0.05)$ or total fungi $(\mathrm{p}=0.01)$ [Table 4]. Hence levels of hBD-2 were increased by the presence of OPC, candida pseudohyphae, total fungi and Candida albicans after 3 months on $\operatorname{ART}(\mathrm{p}=0.002-0.06)$.

Salivary hBD-3 levels were not affected by HIV or ART [Table 1], but were higher in untreated patients with a low fungal burden than in equivalent healthy controls $(\mathrm{p}=0.03)$ and declined marginally on ART in this group ( $\mathrm{p}=0.10)$ [Table 5]. This trend was not evident when patients were stratified by the presence of Candida or OPC.

\section{Discussion}

We present a longitudinal study of immunodeficient HIV patients in an Asian setting examining salivary, behavioural and HIV-associated factors affecting OPC. A high frequency of oral infections was observed, consistent with advanced immunodeficiency (<200 CD4 ${ }^{+}$T-cells/ $\mu \mathrm{l}$ ) before the patients began ART (Bravo et al., 2006). OPC was not significantly linked with smoking even though 50-60\% of participants smoked at some time. Many subjects reported that they did not drink alcohol, as expected in a Muslim country, and alcohol consumption did not affect OPC. 
Candida albicans yeast cell must adhere to host cells and tissue, or co-aggregate with the oral microbiota, in order to colonize and infect (Kanaguchi, Narisawa, Ito, Kinoshita \& Kusumoto, 2012). In a previous study $83 \%$ of otherwise healthy individuals from Eastern Europe with oral Candida had poor oral hygiene and more dental plaque (Muzurovic et al., 2012). However we found no association between poor oral hygiene and OPC, despite a rigorous investigation of oral health and a detailed questionnaire related to tooth brushing and gargling. It may be relevant that the previous study was performed in healthy subjects without advanced immune suppression, whilst here all subjects were in advanced immune suppression, so even subjects with good oral hygiene may be at high risk of having oral candidiasis. Similarly Campisi (2002) that found no evidence that oral hygiene affect oral yeast carriage and dental plaque was not important Candida oral reservoir in non HIV-infected subject (Campisi, Pizzo, Milici, Mancuso \& Margiotta, 2002)

HIV patients were also more likely than controls to have acidic saliva (55 vs 22.5\%). Candida albicans growth and burden have been associated with low salivary $\mathrm{pH}$, which may increase yeast adherence to mucosal epithelial surfaces (Bikandi, Moragues \& Polonelli, 2000). In acidic saliva ( $\mathrm{pH}<6$ ), Candida albicans may grow predominantly in yeast form, while hyphal growth will be induced when $\mathrm{pH}>7$ (Mayer, Wilson \& Hube, 2013). Here salivary acidity did not affect yeast or pseudohyphal counts in patients (data not shown). However the development of hyphae is not solely $\mathrm{pH}$-dependent, temperatures above $37^{\circ} \mathrm{C}$ also have a role ( $\left.\mathrm{Lu}, \mathrm{Su}, \& \mathrm{Liu}, 2014\right)$. This could affected our result, but was not assesed. Elevated temperatures may induce heat shock protein (hsp) 90 to inhibit hyphal development (Lu et al., 2014).

Reduced salivary flow rate can promote OPC by altering the oral microbiota and reducing the cleansing action and antimicrobial components of saliva. These changes promote growth of Candida (Torres et al., 2002). Here the reduced salivary flow rate in HIV patients is in accord with previous studies (Mahajan, Bagul \& Desai, 2015). These authors considered it plausible that decreased salivary flow rate may increase Candida albicans adherence to buccal epithelial cells and hence the risk of OPC, but causation was not established. Accordingly we found no link between hyposalivation and OPC [Table 2]. 
The presence of Candida albicans elevated salivary $\beta$ defensin-2 levels after 3-months on ART, with no clear differences in salivary $\beta$ defensin-3 levels [Tables 1, 4 and 5]. Previous studies reported that the presence of Candida albicans hyphae up-regulates hBD-2 and hBD-3 in epithelial cells (Feng et al., 2005; Cheng, Joosten, Kullberg \& Netea, 2012). Here levels of salivary hBD-2 were marginally higher in untreated patients than controls or patients on ART, and increases triggered by candida and the fungal burden were clear after 3 months on ART. The small differences in salivary hBD-2 levels and lack of any difference with salivary hBD-3 remained following adjustment for salivary total protein concentrations (data not shown). This warrants confirmation in larger studies as poor induction of defensins may have broader effects on the immune system. $\beta$-defensins can promote chemotaxis of dendritic cells, mast cells, neutrophils and T lymphocytes, as well as complement activation (Feng et al., 2005); (Ślebioda, Szponar \& Kowalska, 2013).

Overall the high burden of candidiasis observed here cannot be attributed solely to defects in the induction of $\beta$-defensins. A role for systemic defects in T-cell immunity has been argued as there are clear correlations with a Th1 environment (Zhang et al, 2015). This would be consistent with the parallel between susceptibility to Candida and tuberculosis, and by the resolution of most cases of candidiasis on ART.

\section{Acknowledgements}

The authors thank all patients and controls who participated in this study, and Ms. Faizah who managed the examination schedules, Dr. Silvia Lee from Curtin University who supported laboratory studies, Mr. Ibnu Ariyanto who archived the samples, staff of the Mycology laboratory (Faculty of Medicine, UI), and staff and nurses of HIV clinic (Cipto Mangunkusumo Hospital). This work was supported by International Collaboration Grant from Directorate Research and Community Services, UI [DRPM/PPRLM/105/RKo-UI/2013]. 


\section{Declaration of interest}

The authors report no conflict of interest. The authors alone are responsible for the content and the writing of the paper.

\section{References}

Abiko, Y., Jinbu, Y., Noguchi, T., Nishimura, M., Kusano, K., Amaratunga, P., et al. (2002). Upregulation of Human Beta-Defensin 2 Peptide Expression in Oral Lichen Planus, Leukoplakia and Candidiasis. An Immunohistochemical Study. Pathology. Research \&. Practise, 198, 537-542.

Abiko, Y., Nishimura, M., Kaku, T. (2003). Defensins in saliva and the salivary glands. Med Electron Microscopy, 36, 247-252.

Albanesi, C., Fairchild, H. R., Madonna, S., Scarponi, C., Pità, O. De, Leung, D. Y. M., et al (2007). IL-4 and IL-13 Negatively Regulate TNF- $\alpha$ - and IFN- $\gamma$-induced $\beta$-Defensin expression through STAT-6, Suppressor of Cytokine Signaling (SOCS)-1, and SOCS-3. Journal of Immunology, 179, 984-992.

Alves, T. P., Simoões, A. C. D. C., de Araújo Soares, R. M., Moreno, D. S. A., Portela, M. B., de Araújo Castro, G. F. B. (2014). Salivary lactoferrin in HIV-infected children: Correlation with Candida albicans carriage, oral manifestations, HIV infection and its antifungal activity. Archives of Oral Biology, 59, 775-782.

Benamghar, L., Penaud, J., Kaminsky, P., Abt, F. (1982). Comparison of gingival index and sulcus bleeding index as indicators of periodontal status. Bulletin of the World Health Organization, 60, 147-151.

Bikandi, J., Moragues, M. D., Polonelli, L. (2000). Influence of Environmental pH on the reactivity of Candida albicans with Salivary IgA. Journal of Dental Research, 79,14391442.

Bravo, I. M., Correnti, M., Escalona, L., Perrone, M., Brito, A., Tovar, V., Ri, H. (2006). Prevalence of oral lesions in HIV patients related to CD4 cell count and viral load in a Venezuelan population. Med Oral Patol Oral Cir Bucal, 11, E33-9.

Campisi, G., Pizzo, G., Milici, M. E., Mancuso, S., \& Margiotta, V. (2002). Candidal carriage in the oral cavity of human immunodeficiency virus-infected subjects. Oral Surgery, Oral 
Medicine, Oral Pathology, Oral Radiology, and Endodontics, 93, 281-286.

Carda, C., Carranza, M., Arriaga, A., Díaz, A., Peydró, A., De, M. E. G., Carda, D. C. (2004). Structural differences between alcoholic and diabetic parotid sialosis. Med Oral Patol Oral Cir Bucal, 10, 309-314.

Cheng, S.-C., Joosten, L. A. B., Kullberg, B.-J., Netea, M. G. (2012). Interplay between Candida albicans and the Mammalian Innate Host. Infection and Immunity, 80, 1304-1313.

Chung, W. O., Dommisch, H., Yin, L., Dale, B. A. (2007). Expression of Defensins in Gingiva and Their Role in Periodontal Health and Disease. Current Pharmaceutical Design, 13, 3073-3083.

Diamond, G., Ryan, L. (2012). Beta-defensins: what are they REALLY doing in the oral cavity? Oral Diseases, 17, 628-635.

Espinosa, E., Ormsby, C. E., Gonza, I. (2009). Identification of oral candidosis , hairy leukoplakia and recurrent oral ulcers as distinct cases of immune reconstitution inflammatory syndrome. International Journal of STD \& AIDS, 20, 259-261.

Feng, Z., Jiang, B., Chandra, J., Ghannoum, M., Nelson, S., Weinberg, A. (2005). Human betadefensins: differential activity against candidal species and regulation by Candida albicans. Journal of Dental Research, 84, 445-50.

Gonc, L. S., Ju, A. S., Soares, M., Oliveira, C., Vasconcellos, T., Vianna, M., Regina, S. (2013). Factors associated with specific clinical forms of oral candidiasis in HIV-infected Brazilian adults. Archives of Oral Biology, 58, 657-663.

Greene, J. C., Vermillion, J. R. (1964). The simplified oral hygeine index. Journal of the American Dental Association, 68, 25-31.

Hans, M., Hans, V. M. (2014). Epithelial Antimicrobial Peptides : Guardian of the Oral Cavity. International Journal of Peptides, 2014, 1-13.

Humphrey, S. P., Williamson, R. T. (2001). A review of saliva : Normal composition, flow, and function. Journal of Prosthetic Dentistry, 85, 162-169.

Kanaguchi, N., Narisawa, N., Ito, T., Kinoshita, Y., Kusumoto, Y. (2012). Effects of salivary protein flow and indigenous microorganisms on initial colonization of Candida albicans in an in vivo model. BMC Oral Health, 12, 36-44.

Khan, S. A., Jr, P. L. F., Thunayyan, A. Al, Varlotta, S., Meiller, T. F., Jabra-Rizk, M. A. (2013). Impaired Histatin-5 Levels and Salivary Antimicrobial Activity against C. albicans in HIV 
Infected Individuals. Journal of AIDS Clinical Research, 4, 1-16.

Leao, J. C., Ribeiro, C. M. B., Carvalho, A. A. T., Frezzini, C., Porter, S. (2009). Oral complications of HIV disease. CLINICS, 64, 459-470.

Lu, Y., Su, C., Liu, H. (2014). Candida albicans hyphal initiation and elongation. Trends in Microbiology, 22, 707-714.

Mahajan, B., Bagul, N., Desai, R. (2015). Pseudomembranous type of oral candidiasis is associated with decreased salivary flow rate and secretory Immunoglobulin A levels. Mycopathologia, 180, 75-80.

Mayer, F. L., Wilson, D., \& Hube, B. (2013). Candida albicans pathogenicity mechanisms. Virulence, 4, 119-128.

Muzurovic, S., Babajic, E., Masic, T., Smajic, R., Selmanagic, A. (2012). The Relationship between oral hygiene and oral colonisation with Candida species. Medical Archives, 66, $415-417$.

Nittayananta, W., Kemapunmanus, M., Amornthatree, K., Talungchit, S., Sriplung, H. (2014). Oral human $\beta$-defensin 2 in HIV-infected subjects with long-term use of antiretroviral therapy. Journal of Oral Pathology and Medicine, 42, 53-60.

Ślebioda, Z., Szponar, E., Kowalska, A. (2013). Defensins and their role in the maintenance of the oral cavity homeostasis - a literature review. Central European Journal of Immunology, $38,111-117$.

Soysa, N. S., Ellepola, A. N. B. (2005). The impact of cigarette / tobacco smoking on oral candidosis : an overview. Oral Diseases, 11, 268-273.

Taiwo, O. O., Hassan, Z. (2010). The impact of Highly Active Antiretroviral Therapy (HAART) on the clinical features of HIV - related oral lesions in Nigeria. AIDS Research and Therapy, 7, 19-24.

Torres, S. R., Peixoto, B., Caldas, M. (2002). Relationship between salivary flow rates and Candida counts in subjects with xerostomia. Oral Surgery Oral Medicine Oral Pathology Oral Radiology Endodontics, 93, 149-154.

Zhang, L., Huang, Y., Liu, Z., Liu, W., Qin, Q., Tao, R. (2015). Dynamics of T-cell subsets and their relationship with oral and systemic opportunistic infections in HIV/AIDS patients during the first year of HAART in Guangxi, China. Journal of Medical Virology 87, 11581167 
Table 1. HIV disease and ART affect salivation and candidiasis

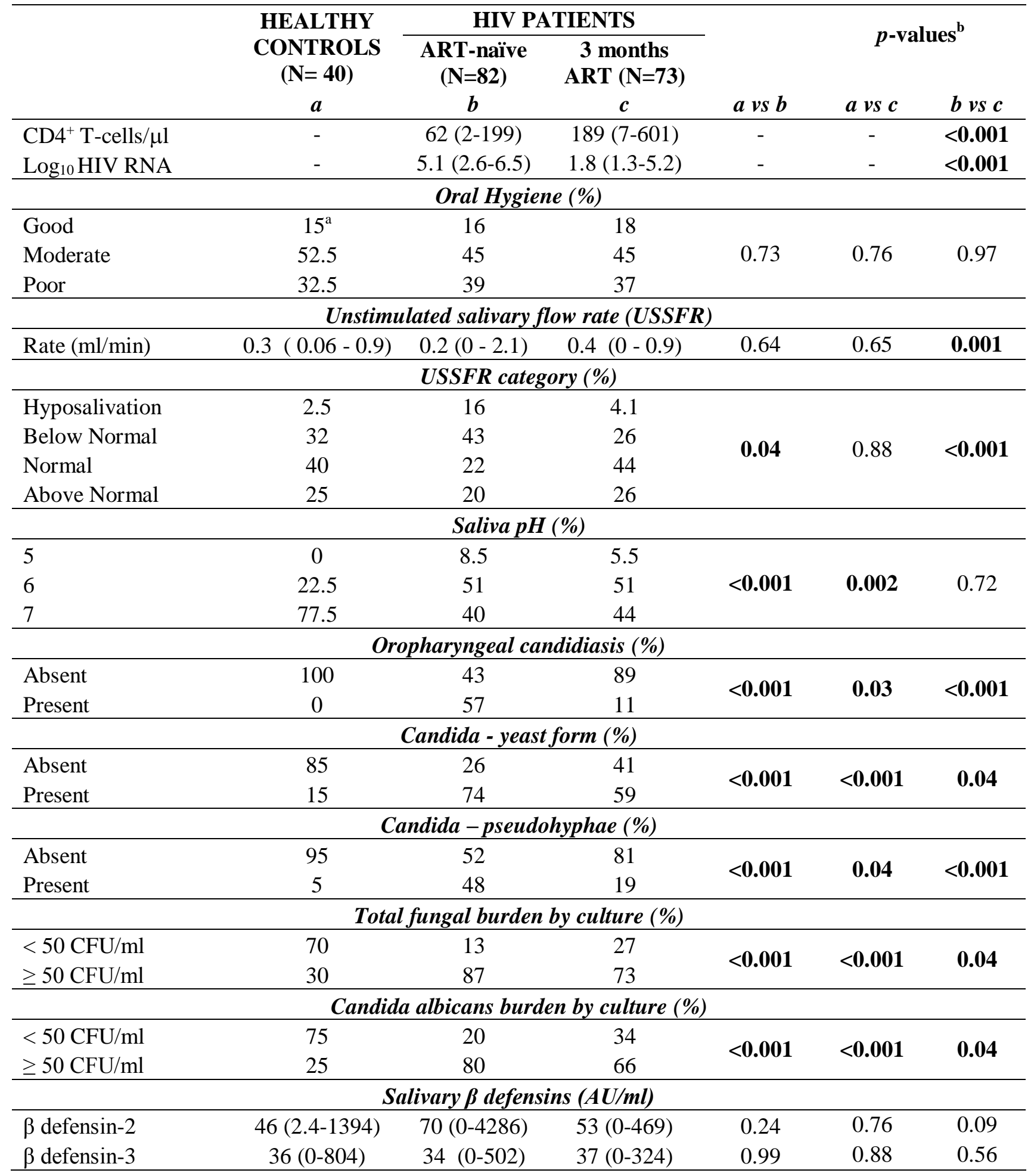

${ }^{\text {a }}$ Percentage of individuals in each category

${ }^{\mathrm{b}}$ Continuous data were analysed by non-parametric Mann Whitney tests and categorical data by $\chi^{2}$ 
Table 2. Fungal burden, Candida yeast and pseudohyphae associate with OPC before ART

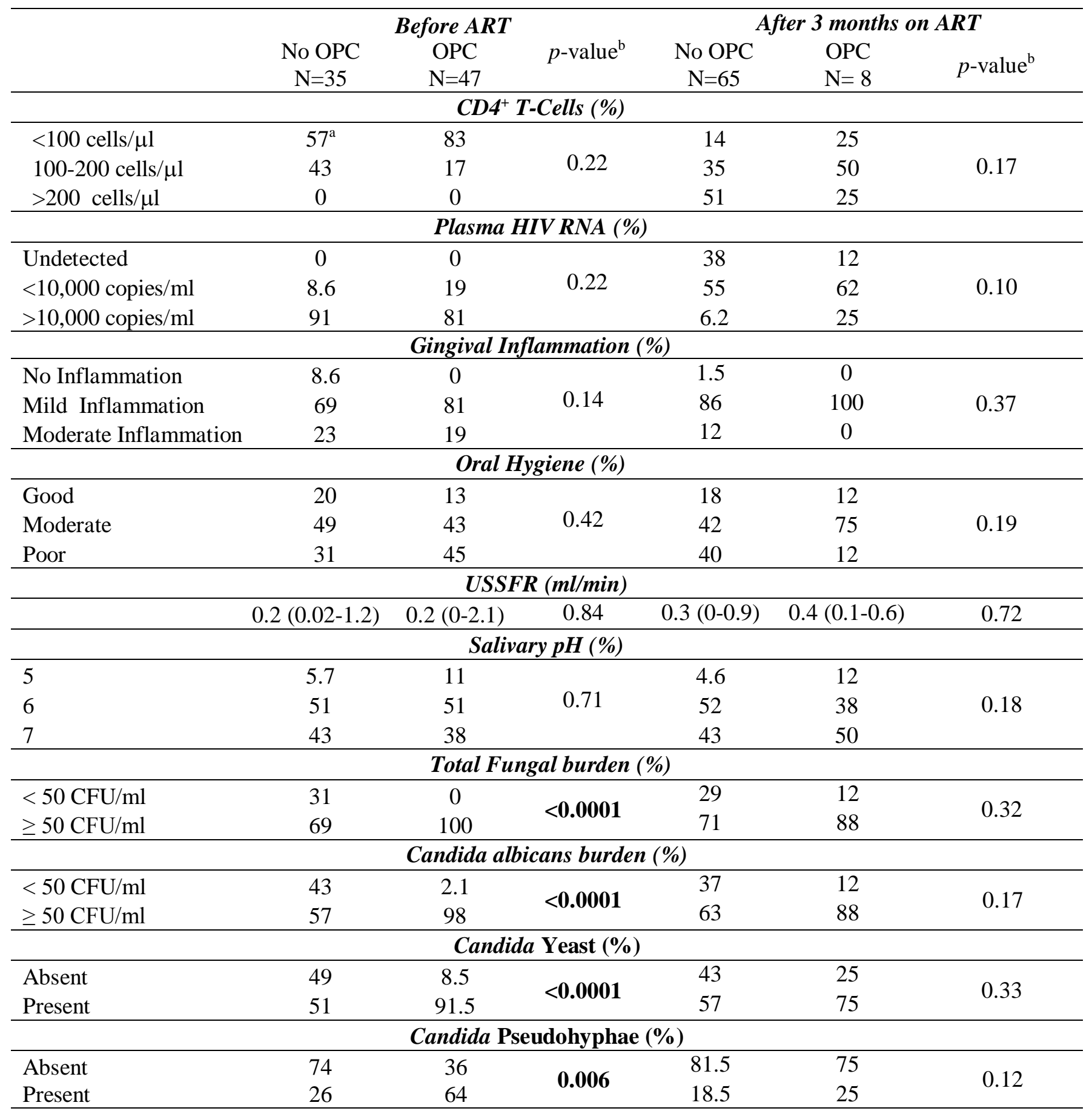

${ }^{\text {a }}$ Percentage of individuals in each category

${ }^{\mathrm{b}}$ Continuous data were analysed by non-parametric Mann Whitney tests and categorical data by $\chi^{2}$ tests 
Table 3. Systemic co-infections associate with OPC, with no clear effect of smoking or oral hygiene

\begin{tabular}{|c|c|c|c|}
\hline & $\begin{array}{c}\text { No OPC } \\
(\mathbf{N}=35)\end{array}$ & $\begin{array}{c}\text { OPC } \\
(\mathrm{N}=47)\end{array}$ & $p$-value ${ }^{\mathrm{a}}$ \\
\hline \multicolumn{4}{|c|}{ Tuberculosis Co-infection (\%) } \\
\hline Absent & 60 & 38 & \multirow{2}{*}{0.05} \\
\hline Present & 40 & 62 & \\
\hline \multicolumn{4}{|c|}{ Hepatitis Co-infection (\%) } \\
\hline No Hepatitis co-infection & 76 & 68 & \multirow{4}{*}{0.02} \\
\hline Hepatitis B co-infection & 6.1 & 6.4 & \\
\hline Hepatitis C co-infection & 6.1 & 25 & \\
\hline Hepatitis B + C co-infection & 12 & 0 & \\
\hline \multicolumn{4}{|c|}{ Smoking habit (\%) } \\
\hline Still smoking & 29 & 32 & \multirow{4}{*}{0.53} \\
\hline Stop $<12$ months & 23 & 30 & \\
\hline Stop $>12$ months & 8.6 & 2.1 & \\
\hline Never smoked & 40 & 36 & \\
\hline \multicolumn{4}{|c|}{ Alcohol consumption (\%) } \\
\hline Still drinking alcohol & 5.7 & 2.2 & \multirow{4}{*}{0.88} \\
\hline Stop $<12$ months & 20 & 26 & \\
\hline Stop $>12$ months & 17 & 17 & \\
\hline Never drank alcohol & 57 & 54 & \\
\hline \multicolumn{4}{|c|}{ Frequency of tooth brushing (\%) } \\
\hline 1 time per day & 11 & 8.5 & \multirow{3}{*}{0.42} \\
\hline 2 times per day & 74 & 85 & \\
\hline 3 times per day & 14 & 6.4 & \\
\hline \multicolumn{4}{|c|}{ Antiseptic mouthwash gargling habit (\%) } \\
\hline No & 77 & 77 & \multirow{2}{*}{0.95} \\
\hline Yes & 23 & 23 & \\
\hline
\end{tabular}

${ }^{\mathrm{a}}$ Categorical data were analysed by $\chi^{2}$ tests 
Table 4. The fungal burden and OPC affect levels of salivary $\beta$ defensin- 2 on ART

\begin{tabular}{|c|c|c|c|c|c|c|}
\hline & \multirow{3}{*}{$\begin{array}{c}\text { HEALTHY } \\
\text { CONTROLS } \\
(\mathrm{N}=40) \\
\text { a }\end{array}$} & \multicolumn{2}{|c|}{ HIV PATIENTS } & \multirow{2}{*}{\multicolumn{3}{|c|}{ p-values }} \\
\hline & & \multirow{2}{*}{$\begin{array}{c}\text { ART-naïve } \\
\begin{array}{c}(\mathrm{N}=82) \\
\text { b }\end{array}\end{array}$} & \multirow{2}{*}{$\begin{array}{c}3 \text { months ART } \\
(\mathrm{N}=73) \\
\text { c }\end{array}$} & & & \\
\hline & & & & $\mathbf{a} v \mathbf{v} \mathbf{b}$ & a vs c & $\mathrm{b} v \mathrm{~s} \mathrm{c}$ \\
\hline \multicolumn{7}{|c|}{ Oropharyngeal candidiasis } \\
\hline Absent & $46(2.4-1394)^{\mathrm{a}}$ & $82(0-1794)$ & $45(0-469)$ & 0.76 & 0.72 & $\mathbf{0 . 0 3}$ \\
\hline \multirow[t]{2}{*}{ Present } & No cases & $66(3.7-4287)$ & $159(1.2-386)$ & - & - & 0.84 \\
\hline & & $p=0.30$ & $p=0.06$ & & & \\
\hline \multicolumn{7}{|c|}{ Candida Pseudohyphae } \\
\hline Absent & $43(2.4-1394)$ & $66(0-1794)$ & $42(0-299)$ & 0.37 & 0.82 & 0.10 \\
\hline \multirow[t]{2}{*}{ Present } & $528(182-874)^{b}$ & $72(0.5-4289)$ & $90(0-469)$ & - & - & 0.86 \\
\hline & - & $p=0.67$ & $p=0.04$ & & & \\
\hline \multicolumn{7}{|c|}{ Total fungal burden } \\
\hline$<50 \mathrm{CFU} / \mathrm{ml}$ & $43(2.4-463)$ & $100(16-234)$ & $13(0-126)$ & 0.07 & 0.06 & $\mathbf{0 . 0 1}$ \\
\hline \multirow[t]{2}{*}{$\geq 50 \mathrm{CFU} / \mathrm{ml}$} & $49(3.8-1394)$ & $66(0-4287)$ & $71(0-469)$ & 0.75 & 0.87 & 0.26 \\
\hline & $p=0.37$ & $p=0.82$ & $p=0.002$ & & & \\
\hline \multicolumn{7}{|c|}{ Candida albicans burden } \\
\hline$<50 \mathrm{CFU} / \mathrm{ml}$ & $43(2.4-463)$ & $49(0-338)$ & $18(0-202)$ & 0.82 & 0.35 & 0.05 \\
\hline \multirow[t]{2}{*}{$\geq 50 \mathrm{CFU} / \mathrm{ml}$} & $115(4.1-1394)$ & $77(0-4287)$ & $62(0-469)$ & 0.63 & 0.38 & 0.20 \\
\hline & $p=0.19$ & $p=0.26$ & $p=0.04$ & & & \\
\hline
\end{tabular}

${ }^{\mathrm{a}}$ Levels of salivary $\beta$ defensin-2 presented in AU/ml

${ }^{\mathrm{b}}$ Positive only in 2 subjects, statistical analysis cannot be performed 
Table 5. Levels of salivary $\beta$ defensin-3 were not associated with OPC, fungal burden, or Candida pseudohyphae

\begin{tabular}{|c|c|c|c|c|c|c|}
\hline & \multirow{3}{*}{$\begin{array}{c}\text { HEALTHY } \\
\text { CONTROLS } \\
(\mathrm{N}=40) \\
\text { a }\end{array}$} & \multicolumn{2}{|c|}{ HIV PATIENTS } & \multirow{2}{*}{\multicolumn{3}{|c|}{$p$-values }} \\
\hline & & \multirow{2}{*}{$\begin{array}{c}\text { ART-naïve } \\
\begin{array}{c}(\mathbf{N}=82) \\
\text { b }\end{array}\end{array}$} & \multirow{2}{*}{$\begin{array}{c}3 \text { months ART } \\
(\mathrm{N}=73) \\
\text { c }\end{array}$} & & & \\
\hline & & & & $\mathbf{a} v s \mathbf{b}$ & a vs c & b vs c \\
\hline \multicolumn{7}{|c|}{ Oropharyngeal candidiasis } \\
\hline Absent & $36(0-804)^{\mathrm{a}}$ & $46(0-300.4)$ & $37(0-324)$ & 0.86 & 0.84 & 0.25 \\
\hline \multirow[t]{2}{*}{ Present } & No cases & $33(0-502.2)$ & $40(0-131)$ & - & - & 1.00 \\
\hline & & $p=0.17$ & $p=0.79$ & & & \\
\hline \multicolumn{7}{|c|}{ Candida Pseudohyphae } \\
\hline Absent & $35(0-624)$ & $43(0-300)$ & $32(0-287)$ & 0.55 & 0.87 & 0.36 \\
\hline \multirow[t]{2}{*}{ Present } & $447(90-804)^{\mathrm{b}}$ & $33(0-502)$ & $53(0-324)$ & - & - & 0.79 \\
\hline & - & $p=0.69$ & $p=0.18$ & & & \\
\hline \multicolumn{7}{|c|}{ Total fungal burden } \\
\hline$<50 \mathrm{CFU} / \mathrm{ml}$ & $32(0-624)$ & $54(9.6-126)$ & $31(0-287)$ & 0.03 & 0.78 & 0.10 \\
\hline \multirow[t]{2}{*}{$\geq 50 \mathrm{CFU} / \mathrm{ml}$} & $60(0-804)$ & $32(0-502)$ & $47(0-324)$ & 0.15 & 0.34 & 0.60 \\
\hline & $p=0.07$ & $p=0.06$ & $p=0.33$ & & & \\
\hline \multicolumn{7}{|c|}{ Candida albicans burden } \\
\hline$<50 \mathrm{CFU} / \mathrm{ml}$ & $34(0-624)$ & $33(0-126)$ & $38(0-287)$ & 0.48 & 0.83 & 0.24 \\
\hline \multirow[t]{2}{*}{$\geq 50 \mathrm{CFU} / \mathrm{ml}$} & $64(0-804)$ & $37(0-502)$ & $34(0-324)$ & 0.31 & 0.32 & 0.60 \\
\hline & $p=0.14$ & $p=0.67$ & $p=0.92$ & & & \\
\hline
\end{tabular}

${ }^{\text {a }}$ Levels of salivary $\beta$ defensin-3 presented in AU/ml

${ }^{\mathrm{b}}$ Positive only in 2 subjects, statistical analysis cannot be performed 


\section{Highlights}

Oropharyngeal candidiasis (OPC) is common in HIV patients beginning ART

We present a study of 82 ART naïve HIV-infected adults beginning ART with $<200 \mathrm{CD}^{+} \mathrm{T}^{-}$ cells/ $\mu$ l at Cipto Mangunkusumo Hospital, Jakarta

At baseline, OPC was detected in 47 patients and linked with a high burden of culturable candida species. No OPC was detected in healthy controls and culture positivity was rare. ART decreased the prevalence of OPC to 8/73 HIV patients re-assessed after 3 months, with reduced total fungal and C. albicans burdens.

Salivary $\beta$-defensin- 2 was elevated in the presence of $C$. albicans hyphae and OPC after 3 months on ART, but $\beta$-defensin-3 was not affected by OPC or ART. 